\title{
Erratum to the Chapter: Small Antennas
}

\section{Kyohei Fujimoto and Zhinong Ying}

The authorship of this chapter has been revised. Zhinong Ying who contributed major parts to the content has been added.

The updated original online version for this chapter can be found at http://dx.doi.org/10.1007/ 978-981-4560-44-3 48.

K. Fujimoto (ه)

Institute of Applied Physics, University of Tsukuba, Tsukuba, Japan

e-mail: hqm11446@flute.ocn.ne.jp

Z. Ying

Research and Technology, Sony Mobile Communications AB, Lund, Sweden

e-mail: Ying.zhinong@sonymobile.com; zhinong_ying@hotmail.com 